\title{
Macrocephaly-intellectual disability-left ventricular non compaction syndrome
}

INSERM

\section{Source}

INSERM. (1999). Orphanet: an online rare disease and orphan drug data base. Macrocephaly-intellectual disability-left ventricular non compaction syndrome. ORPHA:466791

Macrocephaly-intellectual disability-left ventricular non compaction syndrome is a rare, genetic, syndromic intellectual disability characterized by motor and cog nitive developmental delay with language impairment, macrocephaly, hypotonia, dysmorphic facial features (including long face, slanting palpebral fissures and prominent, flattened nose) and left ventricular noncompaction cardiomyopathy. Patients also present skeletal abnormalities (e.g. scoliosis, fing er clinodactyly, pes planus), slender build and shy behavior. Strabismus and various neurological signs (including ataxia, tremor and hyperreflexia) may be associated, as well as epilepsy, autism and MRI findings showing a small cerebellum and abnormalities of the corpus callosum. A phenotypic variant with no cardiac involvement has been reported. 